\title{
As oscilações de estilo no Já Paraíba
}

\section{Oriana de Nadai Fulaneti}

Docente da Universidade Federal da Paraíba (UFPB), Brasil. od.fulaneti@uol.com.br

\section{Dina Pereira de Melo}

Mestre em Linguística pela Universidade Federal da Paraíba (UFPB), Brasil. dinapereirademelo@gmail.com

Resumo: O presente artigo consiste na análise da cobertura de um infanticídio ocorrido em 2013, o caso Fernanda Ellen, pelo jornal sensacionalista Já Paraíba. A leitura das manchetes e reportagens com depoimentos de parentes e policiais envolvidos na investigação mostrou que o éthos do diário sofreu variações que construíram um discurso particularmente distinto da média das matérias comumente publicadas no Já, dada a gravidade das circunstâncias que a tragédia envolvia. Nesse contexto, surge a questão: pode o mesmo diário operar com dois ethé distintos nas coberturas de crimes? Para respondê-la, a contribuição da Semiótica Tensiva pareceu bastante pertinente. Uma análise comparativa entre a cobertura de crimes "previsíveis" contra mulheres e do Caso Fernanda Ellen mostra a existência de gradações de um mesmo éthos no Já Paraíba, além de um frutífero casamento entre éthos e Semiótica Tensiva.

Palavras-chave: Éthos. Semiótica Tensiva. Já Paraíba. Fernanda Ellen.

\begin{abstract}
The present work consists of an analysis of Fernanda Ellen's infanticide news coverage in 2013 by the tabloid Já Paraíba. The reading of the headlines, of her relatives' testimonies and of the police officers who were conducting the investigations revealed that the ethos of the newspaper went through changes that established different discourses from those commonly present in its articles due to the serious circumstances that the tragedy involved. In this context, a question arises: is it possible for the same tabloid to operate with two distinct ethé in the coverage of crimes? To answer the question, the contribution of Tensive Semiotics seemed to be quite pertinent. A comparative analysis between the coverage of "ordinary crimes" committed against women and Fernanda Ellen's murder shows the existence of gradations of the same ethos in Já Paraíba, as well as a fruitful connection between ethos and Tensive Semiotics.
\end{abstract}

Keywords: Ethos. Tensive semiotics. Já Paraíba. Fernanda Ellen. 


\section{Introdução}

A Retórica Antiga revela-se atual em muitos aspectos, sobretudo porque estuda questões de persuasão e de intersubjetividade, levando em consideração a necessidade de o orador se adaptar ao auditório, perspectiva que encontra hoje traços semelhantes em diferentes discursos, como o político, o publicitário, o didático, etc. Nesse sentido, a questão do éthos tem sido retomada e desenvolvida por diversas teorias do discurso, dentre as quais se destacam a teoria da argumentação, a pragmática, a análise do discurso e a semiótica.

Definido como "imagem de si", "caráter mais corporalidade”, "conjunto de hábitos oratórios", "estilo", "modo de dizer", entre outros, o éthos representa um conceito de noção ampla ou, até mesmo, usando as palavras do analista de discurso francês Dominique Maingueneau (2008), "intuitiva”. Para o autor, com quem concordamos totalmente, "o importante, quando somos confrontados com essa noção é definir por qual disciplina ela é mobilizada, no interior de que rede conceitual e com que olhar" (MAINGUENEAU, 2008, p. 12).

Neste artigo, pretendemos abordar o éthos sob o olhar da Semiótica Francesa, buscando trazer algumas contribuições de um desdobramento recente da teoria, a Semiótica Tensiva, que, diferentemente da abordagem greimasiana, focada nas descontinuidades, volta-se para a continuidade e para o intervalo do sentido. A aplicação da tensividade ao éthos será feita na análise de um conjunto de reportagens publicadas no jornal sensacionalista Já Paraíba.

Acompanhando as reportagens sobre crimes contra mulheres que surgiram entre 2009 e 2013, verificou-se que, apesar da regularidade, em alguns casos, havia uma alteração mais acentuada do éthos. É sobre um desses momentos que voltamos o nosso olhar. O caso do assassinato da menina Fernanda Ellen chocou a sociedade em 2013 e, devido à autoria e às circunstâncias brutais associadas à crueldade do infanticídio, experimentou uma curva estésica distinta da que normalmente regia as pautas publicadas pelo jornal, o que nos levou à seguinte pergunta: é possível um mesmo veículo de mídia comportar diferentes ethé (a depender da gravidade do que se 
noticia) ou se trata de variações de um mesmo estilo? A abordagem tensiva pareceu-nos mais adequada para responder a essa questão.

Nessa perspectiva, iniciaremos o artigo com algumas considerações sobre éthos e semiótica. Em seguida, será feita uma breve apresentação do Já Paraíba e, mais especificamente, do corpus selecionado. A terceira seção procura mostrar de forma contrastiva a oscilação do éthos do Já Paraíba. Por fim, realiza-se uma reflexão sobre os resultados da análise e as contribuições da semiótica tensiva para a operacionalidade do conceito de éthos.

\section{Ethos e semiótica}

\subsection{Ethos e semiótica greimasiana}

A semiótica surge no final dos anos 1960 com a proposta de ser uma teoria geral da significação. No intuito de depreender a produção de sentido de um texto, Greimas (1975; 1983; s.d.) desenvolveu uma metodologia que considera a articulação entre um plano do conteúdo e um plano da expressão e categorias que pudessem contemplar a totalidade dos textos manifestados em qualquer materialidade.

Em linhas gerais, a semiótica greimasiana explica a geração do sentido a partir de três níveis no plano do conteúdo: o nível fundamental, no qual se encontra uma oposição semântica mínima responsável pela organização do sentido; o narrativo que, inspirado nos estudos de narratologia de Propp e na antropologia estrutural de Lévi Strauss, busca depreender as constantes das estruturas de transformação narrativa a partir de funções actanciais como destinador, destinatário, sujeito e objeto; o discursivo, em que um sujeito da enunciação assume a produção do enunciado.

Os estudos do nível discursivo exploram bastante a enunciação que, semioticamente, representa uma dupla mediação: por um lado, entre as estruturas sêmionarrativas e o discurso; por outro, entre o discurso e o contexto social e histórico. A teoria greimasiana retoma o conceito de éthos proposto por Aristóteles, associando-o, sobretudo, às relações entre enunciador e enunciatário.

Semioticamente, a reunião do enunciador e do enunciatário, ambos responsáveis pela produção do discurso, constitui o sujeito da enunciação. Esse 
sujeito é concretizado por temas e por figuras, formando o ator da enunciação, que congrega o éthos e o páthos. Dessa forma, o éthos se constrói como a imagem do enunciador do ator da enunciação, a qual não se depreende a partir de um único enunciado, mas de um conjunto de textos. Torna-se, dessa forma, bastante relevante o recorte de uma totalidade, que será constituída de acordo com o objetivo da pesquisa. No presente trabalho, o recorte corresponde a um conjunto de reportagens sobre feminicídio publicadas no Já Paraíba entre 2009 e 2013.

Para depreender o éthos, busca-se, no interior da totalidade estabelecida, encontrar as recorrências existentes, como aponta Fiorin (2004, p. 125):

Onde se encontram, na materialidade discursiva da totalidade, as marcas do éthos do enunciador? Dentro dessa totalidade, procuram-se recorrências em qualquer elemento composicional do discurso ou texto: na escolha do assunto, na construção das personagens, nos gêneros escolhidos, no nível de linguagem usado, no ritmo, na figurativização, na escolha dos temas, nas isotopias, etc.

O éthos do enunciador define-se, portanto, pelas escolhas realizadas pelo sujeito da enunciação na construção de seu objeto, o enunciado. Desse modo, devemos buscar apreendê-lo a partir das recorrências encontradas em todos os níveis dos textos produzidos, ou seja, fundamental, narrativo, discursivo, e em relação com outras totalidades (interdiscurso).

\section{2 Éthos, tensividade e fait divers}

Um dos mais bem-sucedidos desdobramentos da semiótica greimasiana (ou semiótica francesa) é a que se dedica ao exame do campo dos afetos e das emoções transmitidas pelo discurso. Desenvolvida por Claude Zilberberg (2011), esta corrente busca constituir um modelo para descrever os fenômenos contínuos associados ao universo sensível, procurando apreender as grandezas instáveis e sua elasticidade de sentido.

Os princípios em que se baseia estão fundamentados em "Síntese da gramática tensiva" (ZILBERBERG, 2006) e Elementos de semiótica tensiva (ZILBERBERG, 2011). Tensividade é o eixo semântico da coordenada que se desdobra em intensidade e extensividade, valências em que se analisa toda e 
qualquer grandeza linguística. Aquela é da ordem do sensível; a extensividade, do inteligível.

Zilberberg (2006, p. 164-5) contrapõe o par "afetividade" vs. "legibilidade" (numa alusão mais simples, o "sensível” vs. o "inteligível”) para dizer que a afetividade é inerente ao acontecimento e que, como guardião do acento, o acontecimento penetra no espaço tensivo, presidindo a curva tensiva do estado.

Ao construir a sintaxe gráfica, o semioticista francês procurou explicar que o acontecimento é algo tão inescapável no tempo que é incapaz de ser apreendido: quando acontece, já é tarde demais. Por isso ser da ordem dos afetos, "o acontecimento, por ser portador de impacto, manifesta enquanto tal que o sujeito trocou 'a contragosto' o universo da medida pelo da desmedida" (ZILBERBERG, 2011, p. 163). No entanto, tão logo o tempo retome o seu curso e, ao passo que perde em agudeza, o acontecimento ganha em legibilidade.

Prosseguindo, Zilberberg (2011, p. 164-165), ao refletir sobre o conceito de verdade que Greimas havia substituído pelo de veridicção (o importante não está na verdade em si, mas no fazer-crer do destinatário), relacionou, dentro da Semiótica Tensiva, os conceitos de fidúcia (a confiança ou crença) e concessão. A dimensão fiduciária baseia-se na polêmica entre o par crer vs. não crer. Assim, enquanto o objeto do crer é o acreditável, o objeto do não crer é o inacreditável. Zilberberg, da mesma feita, opõe o acreditável vs. inacreditável: crer no acreditável corresponde a uma operação implicativa, da mesma forma que não crer no inacreditável. Entretanto, a concessão está em crer no inacreditável e não crer no acreditável. Para o autor, a concessão dramatiza a veridicção.

O fenômeno do fait divers é o agente estrutural que sustenta a estratégia de espetacularizar os acontecimentos durante a produção noticiosa. São os relatos de crimes, desastres, sexo, roubos, escândalos, bizarrices e excepcionalidades mostrados com importância circunstancial. Para Morin (1977, p. 55):

Os fait divers vão até o fundo da morte, com a lógica irreparável da fatalidade, ao mesmo tempo em que estão integrados à vida cotidiana, sendo consumidos não como um rito criminal, mas na mesa, no metrô, com café e leite [...] as vítimas são oferecidas em sacrifício à infelicidade e à morte. [...] Este sacrifício 
evitaria novos sacrifícios: eles morrem em meu lugar [...] são os outros que morrem e não eu.

Barthes (1964), ao discorrer em ensaio sobre a construção composicional do fait divers, destaca a pouca variabilidade temática, a ênfase no extraordinário e a exacerbação das sensações, no que Landowski (1992, p. 124) complementou, quase três décadas depois, como o "[...] puro estado de alma, em que o cotidiano vivido apenas no modo passional (medo, ódio ou desejo), nada mais é que pretexto para a exaltação das subjetividades". São enunciados que presentificam a dramatis personae conceituada por Barthes (1964, p. 197). Trata-se, na acepção do semiólogo, das essências emocionais que trazem consigo o "germe da degradação", capazes de dar vida aos estereótipos. Os elementos aberrantes, deste ou do além-mundo, povoam o estilo sensacionalista na caracterização de suas personagens.

Acompanhando as reportagens do Já ao longo dos anos, observa-se que, mesmo o diário fazendo usos sensacionalistas do fait divers, há uma alteração no estilo das reportagens e acredita-se que as pesquisas da Semiótica Tensiva possam contribuir para delinearmos as variações no interior desse éthos. 0 que se verifica é a existência de uma espécie de hierarquia dos acontecimentos narrados. Assim, alguns crimes parecem mais previsíveis devido ao caráter habitual, passando a pertencer a uma lógica implicativa; outros crimes, como o caso Fernanda Ellen, são mais chocantes, da ordem da concessão, causando maior impacto.

\section{Já Paraíba: o local sensacional}

Pertencente ao Sistema Correio de Comunicação, o diário Já Paraíba, desde 2009, ano de seu nascimento, vocacionou-se para o segmento popular. Produzido na capital, João Pessoa, o Já circula por todo o estado ao preço de $\mathrm{R} \$ 0,50$, quase exclusivamente pela venda avulsa nas bancas. Seu crescimento junto às classes $C, D$ e $E$ deve-se a uma estratégia que alia baixo custo do produto à falta de concorrência local para o tipo de nicho que explora. 
Figura 1

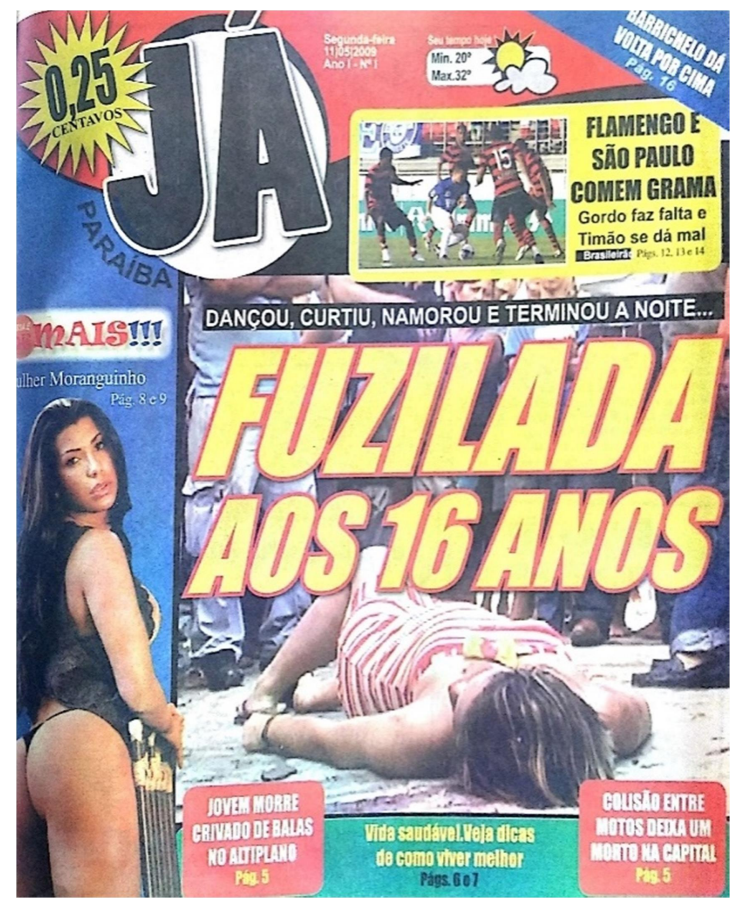

Fonte: Arquivos do Já (11/05/2009)

O impresso está dividido em nove cadernos fixos, que tomam 12 páginas: Supernotas, Cidades, Variedades, Telenotícias, Divirta-se e Esportes. Nota-se que, em contraposição ao que se verifica no jornalismo convencional, não há aqui a seção policial: as notícias afins ocupam a editoria de Cidades. Em Telenotícias, o jornal explora o erotismo, com ensaios de modelos (semi)despidas e as últimas dos famosos ${ }^{1}$.

O diário, em suas notícias, assume o melodrama em duas frentes: ora se entrega ao fait divers, com o propósito assumido de provocar o riso e a afetação, ora assume um tom mais sóbrio e grave, quando os contornos dos acontecimentos pedem moderação. Foi o que aconteceu no caso do assassinato da jovem Fernanda Ellen.

Fernanda Ellen, 11 anos, desapareceu de sua casa, no bairro do Alto do Matheus, no dia sete de janeiro de 2013. Noventa dias após muitos mistérios e boatos, o corpo da menina foi encontrado enterrado na casa do vizinho, o vigia Jefferson Luiz de Oliveira Soares, 25 anos, desempregado. A história

\footnotetext{
${ }^{1} \mathrm{O}$ jornal não conta com site próprio, nem alimenta redes sociais com frequência.
} 


\section{$\mathrm{EI} \square \AA \mathrm{A}$}

ganha contornos sórdidos com o fato de o assassino ter participado de campanhas de buscas da desaparecida. O jornal publicou 29 matérias sobre o que ficou conhecido como o Caso Fernanda Ellen.

Como dito na introdução, este artigo volta-se, sobretudo, para as reportagens do Já publicadas na cobertura do Caso Fernanda Ellen, no intuito de mostrar as oscilações no estilo sensacional do periódico em função da brutalidade do crime. Considera-se, portanto, que uma análise comparativa com o que estamos chamando de "crimes previsíveis" poderá deixar mais clara essa oscilação.

\section{As oscilações do Já}

\subsection{Mortes “previsíveis": estilo exacerbado}

Analisamos, na presente seção, algumas capas, manchetes e reportagens do Já buscando depreender o éthos predominante na cobertura de crimes cotidianos pelo periódico paraibano.

\section{Figura 2}

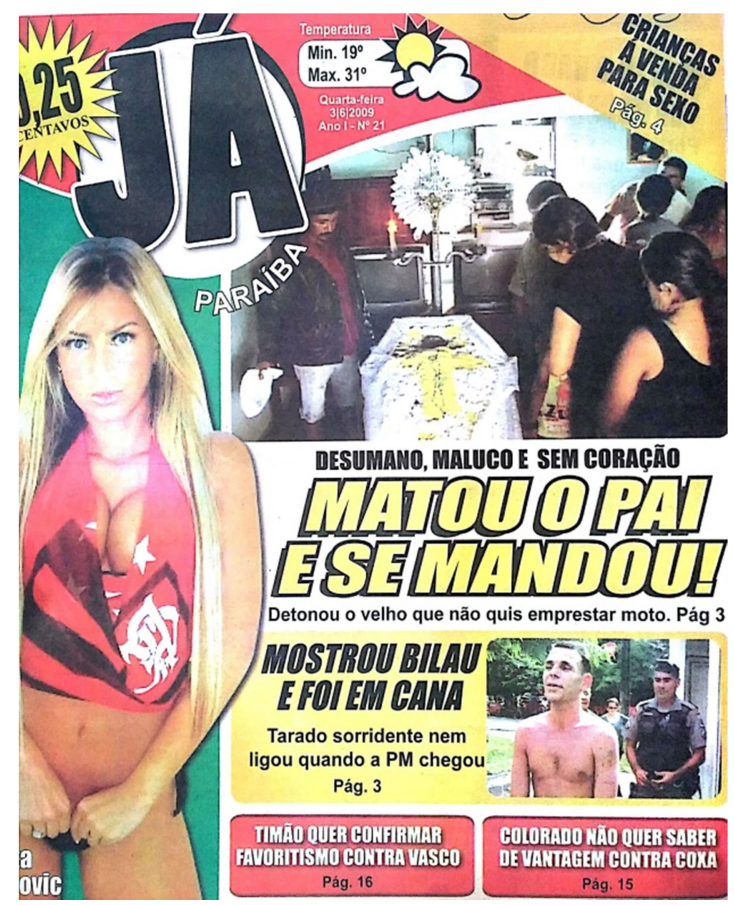

Fonte: Arquivos do Já (03/06/2009) 
No Já, o trinômio sexo-sangue-entretenimento, cuja última variante pode incluir o esporte, está estampado a cada capa, com farto uso de cores berrantes, tipologia chamativa, gírias e palavrões. Há uma dedicação com especial afinco na elaboração dos títulos. Sendo este um dos principais chamarizes para o leitor, viram o espaço da criatividade na exploração de trocadilhos e alusões ao sexo ("Mostrou o bilau e foi em cana", "Cangaia

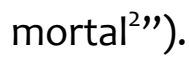

Pela leitura dos títulos, podemos apontar que sexo e violência agrupam as vibrações de olhar e de escuta sobre o mundo, uma competência da qual o destinador-jornal se julga capaz de projetar sobre o destinatário-leitor. Este núcleo temático demanda um núcleo figurativo, em torno do qual gravita outra série de variações de temas e figuras afins: a mulher seminua que invade o jornal evoca o sexo, enquanto a menção à morte e à prisão pespegam o crime.

Observemos a figura 2. Está-se diante de um tema grave, o assédio sexual. Um desempregado foi, em 2009, à Lagoa do Parque Sólon de Lucena (João Pessoa-PB), despiu-se e, segundo apurado com vítimas e policiais, incitou as mulheres passantes ao ato sexual. Aparentava estar bêbado e drogado e foi advertido pelos PMs. Um jornal tradicional provavelmente faria um relato objetivo a partir desse fato. Entretanto, o tratamento discursivo dispensado pelo Já, à luz do fait divers, mais uma vez transforma em chiste o acontecimento. A composição dá maior peso à linguagem não verbal. À postura cômica do acusado, somam-se as figuras "molhar o biscoito" e "arriar as calças" para conferir graça ao enunciado, que despreza o depoimento das vítimas (elas sequer chegaram a ser ouvidas pela reportagem). É como se o jornal elegesse um anti-herói aos moldes de um folhetim, diminuindo a tensão do crime.

Nas reportagens policiais do Já, a atmosfera é de brincadeira com o leitor. A narratividade centra-se predominantemente em ações (ilegais) e em suas sanções. No revestimento temático-figurativo, a permissividade da isotopia da malandragem e do crime muitas vezes é absolvida pelo sujeito da enunciação. A reportagem reproduzida abaixo reforça o tom de informalidade e de brincadeira desse enunciador:

\footnotetext{
${ }^{2}$ Analisado na Figura 3.
} 
Figura 3

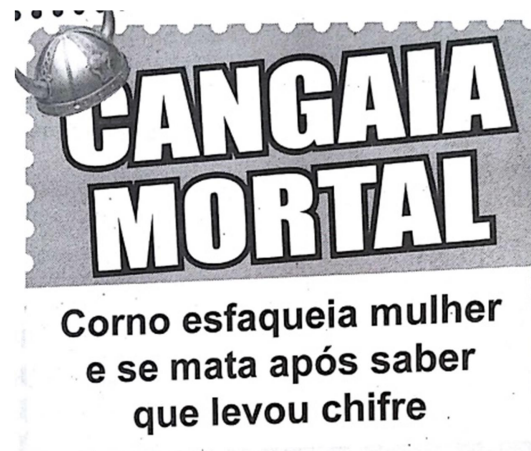

A tragédia aconteceu em Pedras de Fogo, por volta das 11 horas da manhã de ontem. Inconformado com a traição da esposa, o agricultor Cícero Francisco de Moura, de 33 anos, esfaqueou à esposa Cibeli da Silva Moura, de 25 anos. Após o crime, ele fugiu desorientado para um sítio e se matou.

Segundo informações de populares, o casal vinha bringando há alguns dias e Cícero teria cometido o crime por acreditar que estava sendo traído.

Cibele foi socorrida para o Hospital de Emergência e Trauma da Capital onde está internada em estado grave na UTI. Já o corpo de Cícero foi encaminhado para o DML.

Fonte: Arquivos do Já (jun. 09)

As figuras cangaia, corno e chifre e o ícone da "peruca de touro" sobre a letra "c" subtraem a seriedade dos temas "traição", "tentativa de assassinato" e "suicídio" do discurso. O estilo predominante no Já acumula recursos fraseológicos e lexicais excessivamente coloquiais, como gírias e expressões grotescas. O enunciador se permite um estilo de falar à margem da norma para, na aproximação com o seu enunciatário, privilegiar despojamento em detrimento de reflexão e crítica. Ao mesmo tempo em que debocha, reduz pessoas a caricaturas e papéis sociais do imaginário machista, remete a um passado arcaico do homem que esfaqueia a mulher traidora para lavar a honra com sangue, nem que em sacrifício da própria vida.

Ainda com relação a esse universo de depreciação da mulher, observemos a figura 1 /Vida/ e /morte/ são os valores em conflito do nível profundo: a morte (o destaque do plano composicional) está iconizada (reproduz-se a realidade na fotografia), enquanto a vida vem descrita nas ações últimas da vítima. No nível narrativo, a assonância do chapéu da notícia ("Dançou, curtiu, namorou e terminou a noite...") enumera uma série de ações de uma típica jovem que sai para se divertir e fazer coisas de que os 
jovens gostam. A vida, portanto, é eufórica. Já o título traz a disjunção do sujeito com o seu objeto-valor.

Numa leitura sumária do nível discursivo, observamos que a figura jovem de 16 anos, em associação com as demais ("mulher que dança", "mulher que curte" e "mulher que namora" à noite), desvela-se, no percurso figurativo final, em fuzilada (como se em decorrência de uma consequência natural). A suspensão da relação entre causa e consequência da morte da jovem revela um estilo que insinua uma lógica conservadora. No Já muitas vezes a mulher é reduzida nas notícias às estereotipias do universo machista nas matérias: objeto sexual (publicizado nos ensaios eróticos), incapaz, causa de crimes passionais de que são vítimas. Há farto uso de gírias e trocadilhos que depreciam o órgão sexual feminino.

Vemos, na figura 1, um conjunto de elementos que constroem um efeito de sentido hiperbólico: o entorno que realça o preço (então vinte e cinco centavos); as letras que apresentam o nome do jornal e a manchete da reportagem central, maximamente ampliadas e carregadas no negrito; os três pontos de exclamação acompanhando a palavra "mais !!!"; a presença de pouco texto escrito, com predomínio do visual; a grande quantidade de cores; as imagens dilatadas; a diagramação, com a tipografia ocupando o terço central da capa - todo esse conjunto contribui para a configuração de um enunciador do excesso, um sujeito que grita.

Reunindo as características anteriormente apresentadas, verifica-se nas reportagens do Já um estilo que observa um cotidiano de desgraças de perto, de forma ampliada, gritada e maliciosa. Tais características corroboram a descrição feita por Discini (2003, p. 139) acerca dos elementos do éthos sensacionalista.

O éthos de intimidade e deboche garante o estado de alma da malícia, o suporte necessário para seguir tangenciando com graça no mundo do crime, deixando-se marcar na enunciação por um lado, mas eximindo-se de refletir sobre o que fala, por outro. No entanto, veremos adiante que, no tratamento discursivo particular do "caso" Fernanda Elen, a balança pendeu por mais prudência, em detrimento das usuais vedetização e objetificação da figura feminina. 


\section{$\mathrm{EI} \square \mathrm{dA}$}

Figura 4

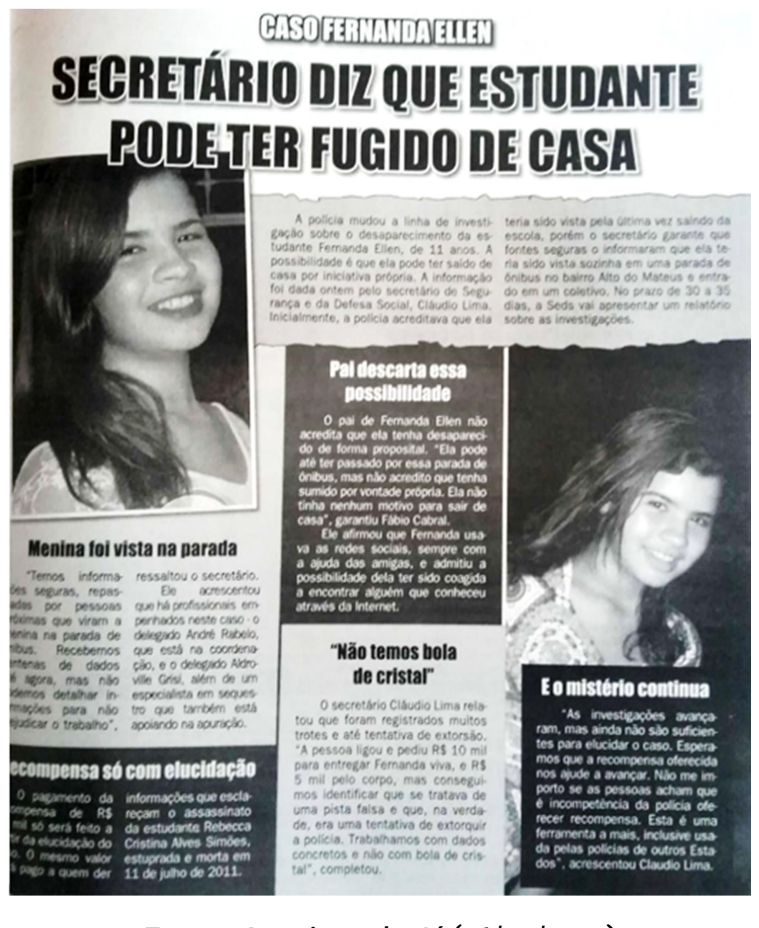

Fonte: Arquivos do Já (16/03/2013)

Pela depreensão do corpus da pesquisa do Caso Fernanda Ellen, a oposição semântica vida vs. morte parece ser a mais óbvia e fácil de identificar. Porém, as oposições de base presentes nas matérias sobre Fernanda (dúvida vs. certeza) estão de tal modo relacionadas a esse outro campo de opostos semânticos (vida vs. morte), que é impossível determinar a sua separação (afinal, a dúvida e a certeza gravitavam em torno da vida ou da morte da menina). Sendo assim, ambos os pares perpassarão juntos todo o nível fundamental da narrativa, numa complementação mútua em que dúvida vs. certeza sobremodalizará a vida vs. morte.

O texto a seguir condensa o quanto aspectos de dúvida e de certeza manifestam-se contraditoriamente nas versões dos entrevistados (delegado e pai da vítima), que, como contrapesos, ora alimentam as esperanças de um reencontro, ora cogitam a sua impossibilidade. 
O delegado geral adjunto de Polícia Civil, André Luís Rabelo, disse que já houve casos em que as pessoas ficaram vários dias desaparecidas e reapareceram bem. "Não temos certeza se ela saiu de casa por livre e espontânea vontade. A situação não é fácil e, assim como acreditamos que poderemos ter uma notícia boa, também há a possibilidade de ter acontecido o pior”, observou.

Família não perde as esperanças

Fábio Júnior Cabral, pai da estudante Fernanda Ellen, disse que com o passar dos dias a apreensão vai se tornando ainda maior, mas a família não perde a esperança de que a garota volte para casa.

"Não estamos descartando nenhuma possibilidade. Quando as pessoas ligam, vamos até o local informado para ver se a encontramos. Cada vez que o telefone toca nossa esperança se renova", lembra Fábio Júnior ("Caseiro pode acabar com sumiço de estudante", 11/01/2013).

De um estado de dúvida quanto à integridade de Fernanda, a família acreditou, por boa parte do tempo, que ela haveria de estar viva em algum lugar. Com o passar dos meses sem notícias da menina, a esperança a que todos se aferravam vai-se esgotando até consumar-se na certeza, por fim, da sua morte. O prolongamento da dúvida contribui para o aumento da tensão.

No nível intermediário da semiose da cobertura do Já sobre o Caso Fernanda Ellen, podemos identificar predominantemente a busca do sujeito (polícia, família, sociedade) em entrar em conjunção com o objeto-valor (verdade). O diário explora o mistério, a angústia e a expectativa da família de obter notícias sobre a jovem desaparecida, como destacado nas partes em grifo abaixo:

\footnotetext{
"A cada dia que passa, a gente vai perdendo as forças, morrendo um pouco, mas sempre peço a Deus algo positivo para que a gente não pense besteira". A declaração emocionada é da avó da estudante Fernanda Ellen Cabral, 11 anos, Luzinete Cabral. [...]
}

A mãe de Fernanda, Elisângela Miranda, também apelou para a população denunciar se tiver alguma informação o paradeiro (sic) da menina. "Nós não queremos vingança, apenas o abraço da minha filha. Faço um apelo para que liguem se souber de alguma informação verdadeira" ("A cada dia morremos um pouco", 18/01/2013, grifos nossos).

A família, aqui manifestada pelas figuras da mãe e avó, conjungiu-se com a tristeza à medida que se disjungiu da presença de Fernanda. Conformada à condição de sujeito de estado, alimentava-se da esperança da performance policial e das denúncias telefônicas para elucidar o caso. Semioticamente, o drama familiar que se percebe resulta de uma sequência narrativa que fica, a maior parte do tempo, refém de uma sanção (= reconhecimento/ 
esclarecimento de um crime e prisão do inimigo). A exploração do mistério, do boato e do sofrimento familiar se reveste de uma série de estratégias sensacionais que produzem um efeito de sentido de expectativa e angústia (espera cada vez mais tensa). Verifica-se que, diferente de casos de crimes “previsíveis", aqui o tom é mais sóbrio, o vocabulário é menos informal, abusa-se menos de gírias e trocadilhos. O jornal não trabalha com a certeza maliciosa, mas com a dúvida insegura, que se torna cada vez mais dolorosa.

O modo como o jornal vai tecendo a história busca provocar no leitor do Caso Fernanda Ellen um percurso passional que, à medida que o crime vai-se resolvendo, oscila da frustração inicial em saber do desaparecimento de uma criança e a solidariedade com a família, até a incredulidade (era preciso crer no impossível) e revolta, ao saber dos detalhes da morte.

Entretanto, para o pai de Fernanda Ellen, o percurso passional foi diferente. No mesmo dia em que o corpo da filha foi encontrado, ele declarou perdoar o assassino. Embora a postura do pai não corresponda ao estilo do Já, o jornal publica a declaração de perdão:

\begin{abstract}
Em meio à revolta da população, uma revelação em especial surpreendeu até mesmo a polícia: o pai da estudante Fernanda Ellen, de 11 anos, disse que perdoa o vigia Jefferson Luiz de Oliveira Soares, de 25 anos, que confessou ter matado sua filha e enterrado o corpo. O caminhoneiro Fábio Júnior, pai da garota, disse que a dor da família não pode ser mensurada, mas não pode haver sentimento de vingança, pois isto não vai trazer sua filha de volta. ("Pai de Fernanda Ellen perdoa assassino da filha", 10/04/2013, grifos nossos).
\end{abstract}

No nível discursivo, a construção do enunciado reforça o efeito de sentido de incerteza apresentado no nível fundamental. Em 16 de março de 2013, o diário estampa: "Secretário diz que estudante pode ter fugido de casa". Segundo a notícia, a especulação do secretário da Segurança e Defesa Social, Cláudio Lima, apostava na chance de fuga da menina por iniciativa própria. Outras manchetes demonstram que a incerteza, manifestada pelo auxiliar "pode", conduziu grande parte das escolhas enunciativas do diário na cobertura do caso. Eis alguns títulos: "Gaiatos podem ser processados" (10/01/2013); "Caseiro pode acabar com sumiço de estudante" (11/01/2013); "Podemos ter notícia boa" (11/01/2013); "Dados podem elucidar casos" (15/01/2013). 
O uso das expressões em grifo não é por acaso. O enunciador estabelece uma oposição entre um eu que não crê e um ele que crê. Ao jogar com tais formas, estabelece-se o jogo enuncivo actancial da modalização sobre a certeza: "pode acabar" não é um "acaba" e "diz que viu" é um outro que vê, em quem jornal e leitor terão que confiar. O boato, no nível discursivo, retoma em sua concretude as oposições semânticas (/certeza/ vs. /dúvida/) da mesma constituição do discurso em seu nível fundamental. À medida que a dúvida se prolonga, a tensão aumenta.

Ainda com relação às categorias enunciativas, a temporalidade das reportagens do Já reforça os elementos passionais de insegurança e angústia. O interstício que separa a saída de Fernanda da escola e a sua não chegada em casa dura uma eternidade para os pais - tanto que os minutos de atraso são sintomáticos de que algo está errado. A separação entre as duas temporalidades instala, pouco a pouco, uma fronteira gráfica nos textos. O religamento entre elas se dará quando a personagem de um dos ambientes invade o outro, isto é, quando o tempo de espera vai ao encontro do tempo da morte.

Semanas antes, vestida com uma camisa em cuja estampa está a foto de Fernanda ladeada pelo aviso "Desaparecida" e os contatos da polícia, a avó, Luzinete Cabral, desabafa: "A cada dia que passa, a gente vai perdendo as forças, morrendo um pouco" (18/01/2013). A manchete do dia reproduz parte do lamento, referenciando uma morte gradual, tortuosa. O tempo foi moldado por uma sucessão de experiências desgastantes de espera, frustração e ansiedade por notícias.

O leitor precisa acompanhar cronologicamente os fatos para descobrir como a família virá saber da morte. Devido ao adiamento da explicação, a notícia ganha um caráter mais dramático (vide as manchetes reproduzindo o lamento dos familiares ou a própria inquirição do jornal, "Onde estará Fernanda Ellen?", de 16 de janeiro de 2013).

Com a elucidação do caso, o diário prossegue seu percurso, explorando detalhes acerca do crime e a biografia do acusado. Ressalta-se, porém, que, diferente de diversos outros casos, o corpo da jovem morta não foi exposto nas páginas do Já e também não houve qualquer insinuação de justificativa ou responsabilização da garota pelo próprio assassinato. Enquanto preservava 


\section{$\mathrm{El} \square \mathrm{dA}$}

Fernanda, o jornal procurava "demonizar" o assassino: "Ele tinha energia negativa" (11/01/2013; "Presos enfurecidos em Jacarapé” (12/11/2013); "Galeria dos monstros" (12/11/2013); "Pra ficar longe do 'capeta"' (15/11/2013).

Jefferson Luiz assume a autoria do crime depois de ter passado três meses fazendo o papel de vizinho retraído. Com a elucidação do caso, o papel temático do assassino recebe revestimentos figurativos mais carregados. Os semas negativa, capeta, monstros e enfurecidos apontam para a construção hiperbólica de um mal revestido pela figura de Jefferson. Do lado oposto estão Fernanda, sua família e até mesmo o cão que guiou os policiais ao corpo, batizado como "Herói". As vítimas retratadas encarnam a pureza, representação repetida pelos entrevistados e utilizada retoricamente pelas autoridades cobradas. Além das vítimas, sofrem os mais próximos, assim como outros personagens não diretamente relacionados. A construção antitética reforça a necessidade de o Já estabelecer universos apartados pelo discurso maniqueísta. $O$ discurso elege a todo tempo personificações do bem e do mal que convivem no mesmo espaço, mas cujos valores jamais se tocam.

\section{Figura 5}

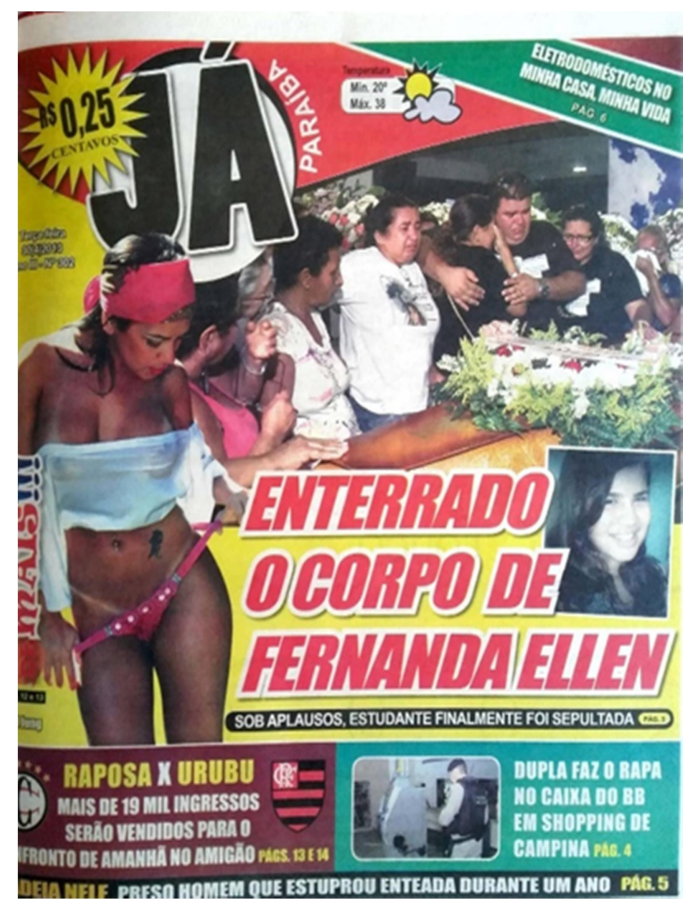

Fonte: Arquivos do Já (30/04/2013) 
A montagem de capa do Já sobre o velório da Fernanda (30/04/2013) também opera o trinômio sexo-violência-esporte, a dilatação da imagem, das cores, das letras e do negrito. Todavia, neste caso, não há trocadilhos, nem piadas, nem malícia. Na foto menor, sobreposta, Fernanda sorri. Na maior, o seu corpo velado pelos pais, a avó e outros. É o antes e depois do acontecimento-morte. A tensão produzida pelo cotejo entre as imagens da menina e do seu funeral reforça o sentimento de inocência da criança frente à perfídia da vida urbana e da natureza humana. O sentido de injustiça do teatro melodramático constrói-se entre uma imagem e outra - entre o tempo de paz e o da morte.

Dentro da inscrição gráfica da sintaxe tensiva da semiose, uma criança que desaparece sem porquê é um acontecimento, mas o vizinho conhecido que mata uma criança é um acontecimento maior em sua gradação tônica. $O$ vizinho que mata por motivo torpe ascende ainda mais na curva valencial do acontecimento à medida que o leitor chega a este conhecimento. E esta tonicidade tende a seguir num crescendo quando da desova do corpo, da participação de Jefferson nos atos públicos em busca de Fernanda, enfim, da constatação do sujeito leitor que é levado a crer no inacreditável (no concessivo) das revelações.

Sob o espectro da Semiótica Tensiva, portanto, a análise tende a tornar mais intenso, sensorial e estésico o caráter da veridicção, intensificando-a, levando ao espanto e tendendo à saturação. As narrativas que envolvem o caso Fernanda Ellen detonam o acontecimento do ponto de vista valencial, por se situar no espaço da desmedida, do paroxismo, das situações inacreditáveis, tal como Mendes (2013, p. 140) relacionou a estesia à veiculação da cobertura sobre o Caso Isabella Nardonni pelo Jornal Nacional, em 2008:

No espaço tensivo, o sujeito semiótico (enunciatário), ao longo dessas reportagens, percebe uma intensidade inicialmente já elevada, mas que tende a subir com o passar do tempo. Noutros termos, a presença desse fait divers, diariamente, na pauta do noticiário, em que cada reportagem apresenta um novo elemento ou retoma um elemento já sabido, intensifica o fato semiótico em questão.

Se convencionarmos chamar de "A" as notícias do universo sensacionalista comumente veiculadas no Já e de " $B$ " as que deram conta da 
cobertura do Caso Fernanda Ellen, e posicionando ambos os pontos na curva valencial dos eixos de tensividade,

Figura 6: Simulação da comparação tensiva entre o Caso Fernanda (B) e as pautas do Já (A)

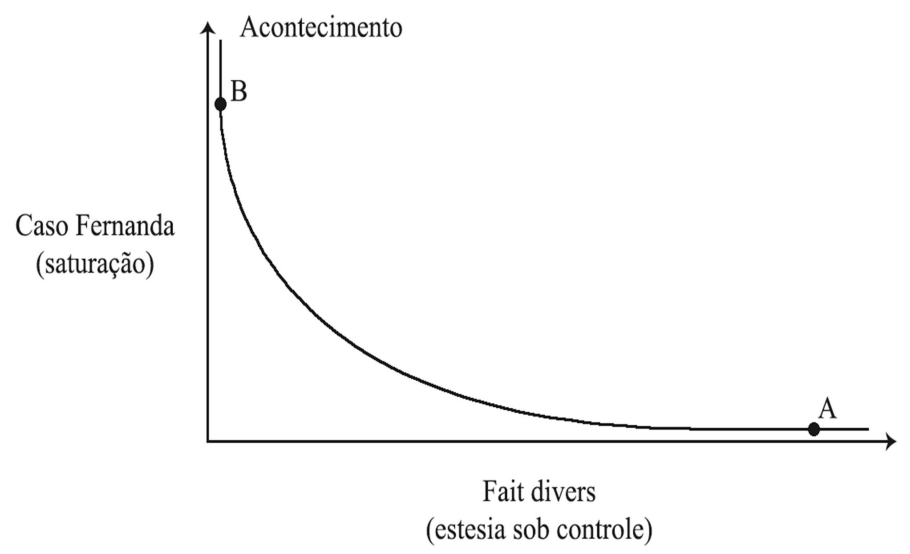

percebemos que há uma relativa constância em A do ponto de vista dos afetos mobilizados na percepção do leitor - até porque, em se tratando de um veículo sensacionalista, a exploração de notícias insólitas, fantásticas, violentas (em certa medida) ou que despertem o chiste e o erotismo é o esperado, o padrão e não escapa a essa normalidade. Já as revelações em B, especialmente quando da descoberta dos detalhes sórdidos do crime, de ter sido cometido contra uma criança, da extensa cobertura dedicada ao seu paradeiro, da conduta insuspeita do latrocida e do drama familiar envolvem tal grau de saturação dos afetos no enunciatário que detonam o acontecimento em seu maior acento valencial - distanciando-se, portanto, do tratamento discursivo normalmente trabalhado em outras reportagens.

A curva inversa do Já Paraíba demonstra, portanto, não dois ethé, mas duas gradações de um mesmo caráter que, dada a comoção social e crueza do crime, pendeu por contenção. Isso nos leva a concluir que, nas notícias que exploram o gênero fait divers dentro de uma mídia naturalmente acostumada a navegar neste gênero, quanto mais sensacionalista, menor o grau de envolvimento estésico da parte do enunciatário. De forma inversa, quanto menos reunir elementos de fait divers, maior a tensão afetiva mobilizada. 


\section{Considerações finais}

As análises anteriores são de capas e reportagens do Já sobre crimes contra mulheres ocorridos entre 2009 e 2013. Elas têm em comum diversos elementos, entre os quais se destacam a diagramação; o excesso visual, com muitas cores, imagens, letras grandes e em negrito; o contexto sexo-violênciaentretenimento; a exploração exacerbada do crime, entre outros. Entretanto, as análises também mostram que o diário lança mão de recursos um pouco distintos na construção de suas reportagens, de acordo com a natureza do crime. Na maioria dos casos, o registro é mais informal, cheio de trocadilhos e duplo sentido, o enunciador é seguro e mostra certezas, o tom é de deboche e malícia, a figura dos criminosos constrói-se como uma espécie de anti-herói, as mulheres são inferiorizadas e, muitas vezes, insinua-se que são responsáveis pela própria morte devido ao "mau" comportamento. As tragédias são “previsíveis”, vividas por pessoas “menores” e, portanto, provocam o riso.

Por outro lado, em algumas reportagens, verificamos um tom mais formal, a exploração da dúvida e da angústia, o recurso do maniqueísmo. A vítima é "santificada", e o vilão, "demonizado". São crimes tão chocantes que se tornam sérios, eles não cabem na comédia dramática, pedem o puro drama.

Espera-se com esta análise ter demonstrado a frutífera contribuição da semiótica tensiva para a depreensão do éthos, um poderoso conceito que surge na Retórica e passa a ser adotado por diferentes teorias do discurso. A abordagem do éthos da perspectiva de suas gradações certamente aplica-se a discursos de outra natureza além do midiático, entre os quais destacamos o político, tão elástico ultimamente.

\section{Referências}

BARROS, Diana Luz Pessoa de. Teoria semiótica do texto. São Paulo: Martins Fontes, 2002.

BARTHES, Roland. A estrutura dos fait divers. Essais critiques. Paris: Seuil, 1964. Disponível em: http://www.eca.usp.br/jorlingrad/estrutura\%2obarthes.doc

DISCINI, Norma. O estilo nos textos - histórias em quadrinhos, mídia, literatura. São Paulo: Contexto, 2003. 
FIORIN, José Luiz. Elementos de análise do discurso. São Paulo: Contexto, 2016.

FIORIN, José Luiz. O éthos do enunciador. In: CORTINA, Arnaldo; MARCHEZAN, Renata Coelho (Org.) Razões e sensibilidades: A semiótica em foco. Araraquara: Laboratório Editorial/FCL/UNESP; São Paulo: Cultura Acadêmica Editora, 2004.

GREIMAS, Algirdas Julien. Sobre o sentido II. Ensaios Semióticos. Petrópolis: Vozes, 1975.

GREIMAS, Algirdas Julien. Du sens II. Paris: Seuil, 1983.

GREIMAS, Algirdas Julien; COURTES, Joseph. Dicionário de semiótica. São Paulo: Cultrix, s.d.

LANDOWSKI, Eric. A sociedade refletida. São Paulo: Educ, 1992.

MAINGUENEAU, Dominique. Cenas da enunciação. Organizado por Sírio Possenti e Maria Cecília Pérez de Souza-e-Silva, diversos tradutores. Curitiba: Criar Edições, 2006.

MAINGUENEAU, Dominique. A noção de ethos discursivo. In: MOTTA, Ana Raquel, SALGADO, Luciana. (Org.). Ethos discursivo. São Paulo: Contexto, 2008.

MELO, Dina Pereira de. Fait divers e estesia: o sensacionalismo revelado nas narrativas do Já Paraíba. 2018. Dissertação (Mestrado em Linguística). Programa de Pós-Graduação em Linguística. Universidade Federal da Paraíba, 2018.

MENDES, Conrado Moreira. Semiótica e mídia: uma abordagem tensiva do fait divers. 2013. Tese (Doutorado em Semiótica e Linguística Geral). Programa de Pós-Graduação em Linguística. Universidade de São Paulo.

MORIN, Edgar. Cultura de massas no século XX: o espírito do tempo. Rio de Janeiro: Forense Universitária, 1977.

ZILBERBERG, Claude. Síntese de Gramática Tensiva. Significação. Revista Brasileira de Semiótica, São Paulo, n. 25, p. 163-204, 2006.

ZILBERBERG, Claude. Elementos da semiótica tensiva. Cotia: Ateliê Editorial, 2011.

Forma de citação sugerida

FULANETI, Oriana de Nadai; MELO, Dina Pereira de. As oscilações de estilo no Já Paraíba. EID\&A - Revista Eletrônica de Estudos Integrados em Discurso e Argumentação, Ilhéus, n. 19, p. 83-102, ago.2019. DOI dx.doi.org/10.17648/eidea-192410. 